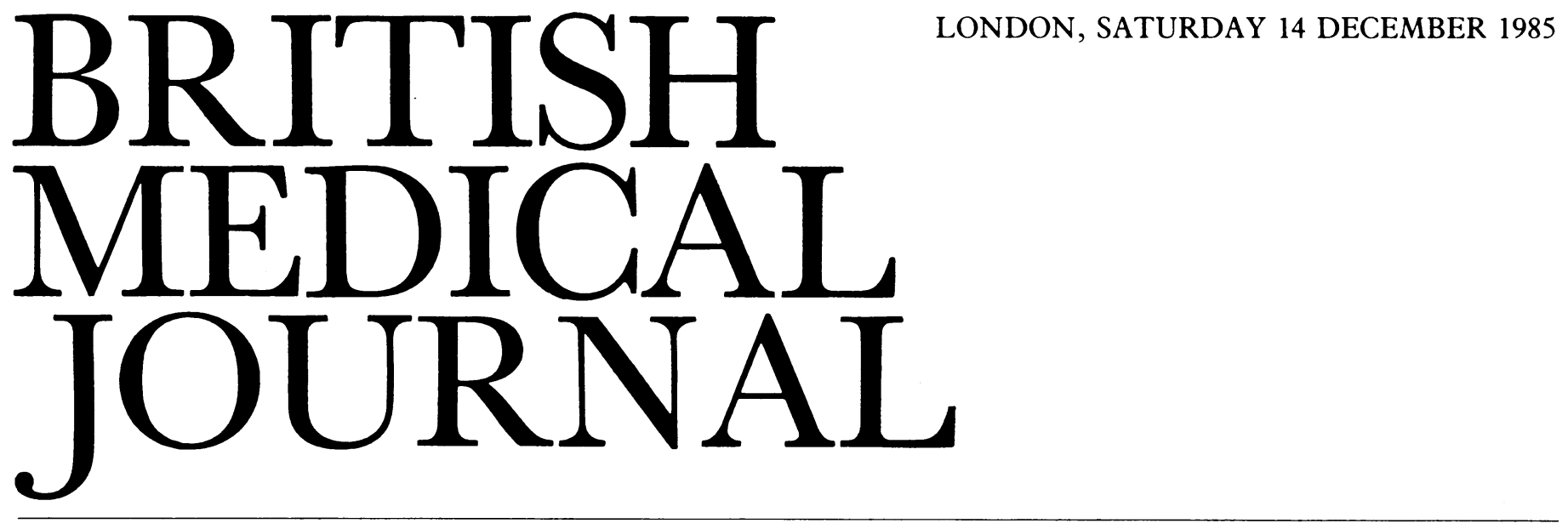

\title{
Catching up the Europeans in preventing heart disease
}

Mortality from cardiovascular disease in the United Kingdom compares poorly with other countries in Western Europe; Northern Ireland and Scotland have particularly high rates. ${ }^{1}$ The results of the prospective phase of the British Regional Heart Study provide an opportunity to review current knowledge of cardiovascular risk factors based on data from middle aged (40-59) men in 24 towns. ${ }^{2}$

The results have confirmed the importance of cigarette smoking, raised blood pressure, and raised serum cholesterol concentrations as risk factors for ischaemic heart disease (acute myocardial infarction or sudden death). Obesity was a risk factor when considered alone but seemed to exert its effect through its influence on blood pressure and cholesterol. Cigarette smoking trebled the risk above the rates in men who had never smoked. Raised systolic blood pressure doubled the risk when it was more than $148 \mathrm{~mm} \mathrm{Hg}$ (the top $40 \%$ of men). The risk was also doubled in the top fifth of the body mass index relative to the lowest fifth-a difference in weight of around $20 \mathrm{~kg}$. A continuous and substantial increase in risk was observed with increasing serum cholesterol concentrations. Men in the top fifth had a threefold increase in risk compared with those in the bottom fifth of the range of serum cholesterol values. A raised cholesterol concentration seemed to be a risk factor for subsequent ischaemic heart disease in those with pre-existing ischaemic heart disease at entry.

Data of this kind show the importance of prevention, and the responsibility for this task falls mainly on those providing primary health care. General practitioners have regular contact with most of their patients, and their practice list comprises a relatively well defined population. ${ }^{3}$

The first priority must be to stop smoking. The contribution of the general practitioner to persuading patients to stop smoking has been shown to give success rates of $5-10 \%$. These figures may be well below those hoped for in therapeutic interventions but if all general practitioners made the effort they would have an impact. ${ }^{4}$

Next, the treatment of asymptomatic hypertension is mainly justified by the reduction it produces in the incidence of stroke, but the recent Medical Research Council mild hypertension treatment trial suggested another possible gain-a reduction in coronary events among non-smoking patients with hypertension treated with propranolol' similar observation was noted for men in the International
Prospective Primary Prevention Study in Hypertension trial. ${ }^{6}$ The control of hypertension in the community still leaves a lot to be desired; many patients are given inadequate treatment and their follow up is irregular. ${ }^{78}$

There is still controversy over whether attempts to prevent ischaemic heart disease by lowering serum cholesterol concentrations should be based on selective intervention in high risk subjects or on shifting the risk profile of whole populations. A strong argument for the second approach is that epidemiologists have little ability to predict the future of any one patient. ${ }^{9}$ In British middle aged men the use of the 80 th percentile of the cholesterol concentration for identification of a high risk group would result in the inclusion of only around a third of those who would subsequently develop clinical ischaemic heart disease. ${ }^{10}$

Earlier this year the National Institutes of Health consensus development conference recommended intensive dietary intervention for people in the United States in the top quarter of the distribution of cholesterol values-with the addition of appropriate drugs for the top 10th if the response to diet was inadequate. "To apply similar cut off points to the British population would include around half of all middle aged men because of their high plasma cholesterol concentrations. ${ }^{10}$ The consensus development conference also recommended a reduction in total dietary fat from $40 \%$ to $30 \%$ of total energy, including a reduction of saturated fat intake to less than $20 \%$ of total energy, and an increase in polyunsaturated fat to not more than $10 \%$ of total energy for the United States population. In Britain the Department of Health has recommended less dramatic reductions in total fat and saturated fat to $35 \%$ and $15 \%$ respectively of total energy. ${ }^{12}$

When patients ask about this continuing controversy we need to explain that the whole population approach and the high risk approach are complementary and not antagonistic. All are agreed on the need to screen all first degree relatives of patients who develop coronary artery disease under the age of $50 .{ }^{13}$ It seems reasonable to expend rather more resources on attempting to modify risk factors in those people who are at "high risk"- but not to the exclusion of programmes aimed at those who are individually at somewhat lower risk but will contribute larger numbers of cases. Programmes for prevention including practice nurses, general practitioners, and other members of the primary health care team could help to reduce cardiovascular risks in the population. ${ }^{14}$ At present 
most general practitioners do not employ the full quota of practice staff for which they can claim reimbursement.

Rigorous evaluation of preventive activities is needed so that they may be further modified and improved in the light of experience. In particular, a comparison of programmes with and without measurements of the plasma cholesterol concentrations would allow assessment of the relative costs, acceptability, effectiveness, and logistical problems. Questions still remain about the optimum diet for reducing cardiovascular risk (and cancer), but a reduction in fat intake and perhaps an increase in vegetable intake (including sources of dietary fibre) seem likely to reduce both. ${ }^{12} 15-17$ Other factors, particularly haemostatic variables, are likely to be independent determinants of cardiovascular risk which may also be susceptible to dietary influences. ${ }^{18-20}$

The uncertainties which persist should not, however, be a justification for inaction. If the poor record of the United Kingdom in ischaemic heart disease is to be reversed general practitioners and other primary care professionals will have to rise to the challenge both in their day to day work and by participating in research to resolve the remaining elements of uncertainty.

Consultant,

ANDREW P HAINES

Medical Research Council Epidemiology and Medical Care Unit,

Northwick Park Hospital,

Harrow, Middlesex HAl 3UJ
1 Uemura K, Pisa Z. Recent trends in cardiovascular disease mortality in 27 industrialized countries. World Health Stat $Q$ 1985;38:142-62.

2 Shaper AG, Pocock SJ, Walker M, Phillips AN, Whitehead TP, Macfarlane PW. Risk factors for ischaemic heart disease: the prospective phase of the British Regional Heart Study. $\mathcal{F}$ Epidemiol Community Health 1985;39:197-209.

3 Cartwright A, Anderson R. Patients and their doctors. London: Royal College of General Practitioners, 1977. (Occasional Paper, No 8.)

4 Russell MAH, Wilson C, Taylor C, Baker CD. Effect of general practitioner advice against smoking. Br Med f 1979;ii:221-5.

Medical Research Council Working Party. MRC trial of treatment of mild hypertension: principal results. Br Med f 1985;291:97-104.

The IPPPSH Collaborative Group. Cardiovascular risk and risk factors in a randomized trial of treatment based on the beta-blocker oxprenolol: the International Prospective Primary Prevention Study in Hypertension (IPPPSH). Joumal of Hypertension 1985;3:379-92.

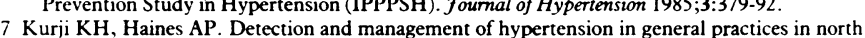
west London. BrMed f 1984;288:903-5.

8 Michael G. Quality of care in managing hypertension by case finding in north west London. $\mathrm{Br}$ Med F 1984;288:906-8.

Med $\mathcal{F}$ 1984;288:906-8.
9 Rose G. Sick individuals and sick populations. Int f Epidemiol 1985;14:32-8.

10 Shaper AG, Pocock SJ. British blood cholesterol values and the American consensus. Br Med $\mathcal{F}$ $1985 ; 291: 480-1$

11 Office of Medical Applications of Research, National Institutes of Health. Consensus conference. Lowering blood cholesterol to prevent heart disease. FAMA 1985;253:2080-95.

12 Department of Health and Social Security. Diet and cardiovascular disease. London: HMSO, 1984. (Report on Health and Social Subjects, No 28.)

13 Oliver MF. Strategies for preventing and screening for coronary heart disease. Br Heart $\mathrm{f}$ 1985;54:1-5.

14 Fullard E, Fowler G, Gray JM. Facilitating prevention in primary care. Br Med $\mathcal{f}$ 1984;289: $1585-7$.

15 Committee on Diet, Nutrition and Cancer. Diet, nutrition and cancer. Assembly of life sciences, National Research Council. Washington, DC: National Academy Press, 1982.

16 Kushi LH, Lew RA, Stare FJ, et al. Diet and 20-year mortality from coronary heart disease. $N$ Engl f Med 1985;312:811-8.

17 Morris JN, Marr JW, Claydon DG. Diet and heart: a postscript. Br Med f 1977;ii: 1307-14

18 Meade TW, North WRS, Chakrabarti R, et al. Haemostatic function and cardiovascular death: Meade TW, North WRS, Chakrabarti R, et al. Haemostatic
early results of a prospective study. Lancel 1980;i:1050-4.

19 Meade TW, Chakrabarti R, Haines AP, North WRS, Stirling Y. Characteristics affecting fibrinolytic activity and plasma fibrinogen concentrations. Br Med $\mathcal{F}$ 1979;i:153-6.

20 Haines AP, Chakrabarti R, Fisher D, Meade TW, North WRS, Stirling Y. Hemostatic variables in vegetarians and non-vegetarians. Thromb Res 1980;19:139-48.

\section{Irritability}

In ordinary speech irritability implies poor control of temper resulting in an external display such as quarrelling. As such we are all irritable at some time or other and are so, we hope, without any disorder of our mind. Irritability is also, however, a common complaint in general practitioners' surgeries and the outpatient clinics of psychiatrists, neurologists, and neurosurgeons. If the patient does not admit to it, which is unusual, the relatives certainly will. In these patients irritability has become abnormal either because it is a new characteristic in a person not normally irritable or it is present to an abnormal degree.

So what do we mean by "irritability," and if we can define it is it important? Should the definition include any mood change which results in external physical aggression, and, by contrast, can a person be irritable even without external signs?

An initial attempt at a definition used the words "irritable aggression."' Unfortunately, this definition contained within it the attempt to harm, which most of us would not accept as a feature of irritability. Recognising this, a recent paper has suggested that, although "irritability" and "irritable aggression" are probably at opposite ends of a spectrum, the important feature of irritability is that it does not include any attempt to harm..$^{2}$ The authors proposed a definition of irritability as "a fuming state characterised by reduced control over temper which usually results in irascible, verbal, or behavioural outbursts, although the mood may present without observed manifestations...." Included in this was the fact that irritability may occur for either brief or prolonged periods, is always unpleasant for the individual (lacking the cleansing effect of justified outbursts of anger), and may be present without any overt verbal or physical manifestations. Irritability may be associated with other symptoms such as depression or anxiety, but it is an independent mood and is not merely symptomatic of these states.

Brain damage is an important factor in generating irritability. The limbic system has been suggested as the site of the damage, but no specific area has been implicated with certainty. Chemical changes are also important. Alcohol is well known for its effect on mood: both irritability and aggressive behaviour may be symptoms of alcohol intoxication or, more likely, withdrawal. Indeed, people recovering from head injuries should be warned to use alcohol sparingly for this reason-as well as for fear of precipitating seizures. In any individual case, however, it may be difficult to establish a causal relation between alcohol and irritability; personality factors, existing psychiatric disorders, and social problems may all complicate the picture. Hormones too play a part: irritability may be a prominent feature within the postnatal ${ }^{3}$ and paramenstrual periods. ${ }^{24}$

In the clinical setting a head injury, even a minor one, is one of the most common causes of irritability. ${ }^{5-8}$ It forms part of the post-traumatic syndrome and is usually the result of brain damage. ${ }^{x}$ Even a minor head injury may cause some slight brain damage, which may impair the processing of information. ${ }^{910}$ Possibly this subtle deficit, with its resultant frustration, produces the irritability. The relevance of a compensation claim is often exaggerated.'

Managing irritable patients with head injuries may be awkward but is not difficult. Both the patient and the relatives should be told about the possible organic basis, especially after a minor head injury. Alcohol intake should be limited. Other than this, time and sympathy is all that can 